\title{
As imagens de Debret no ensino de história no Liceu do Ceará, Fortaleza (Bairro Jacarecanga)
}

\author{
Antônio Germano Magalhães Junior* \\ Adriano Cecatto**
}

\begin{abstract}
Resumo
Propomos investigar a prática de ensino dos professores de História com o uso de imagens. O estudo objetiva compreender como os professores de História do Liceu do Ceará podem utilizar mais proficientemente as iconografias de Jean-Baptiste Debret para lecionar História no ensino médio. As fontes de pesquisa são as entrevistas e a bibliografia consultada. Analisou-se nas entrevistas a concepção de imagem e de sua condizente utilização em sala de aula. O referencial teórico-metodológico se fundamenta na História Cultural, partindo do conceito de representação elaborado por Roger Chartier $(2002$; 1991) e a leitura de imagens proposta por Peter Burke (2004) e Sandra JatahyPesavento (2008). Constatou-se que a utilização das imagens de Debret tiveram significado, quando relacionadas com outras linguagens e estabeleceram associações com diferentes tempos históricos. Á medida que os docentes dialogam com outras áreas do conhecimento, constitui-se bases teóricas que permitem a utilização de imagens no ensino de História.
\end{abstract}

Palavras-chave: Ensino de História; Imagem; Jean-Baptiste Debret.

\section{Debret's images in teaching history in Liceu Ceará, Fortaleza (Jacarecanga)}

\begin{abstract}
We propose to investigate the practice of teaching of history teachers with the use of images. The study aims to understand how history teachers of the Lyceum of Ceará could use more proficiently the iconography of JeanBaptiste Debret to teach history in high school. The research sources are interviews and the consulted bibliography. We analyzed in the interviews the conception of image and and the consistent use in the classroom. The theoretic methodological framework is based on Cultural History, starting from the concept of representation elaborated by Roger Chartier $(2002$; 1991) and reading of images proposed by Peter Burke (2004) and Sandra JatahyPesavento (2008). It was found that the using of Debret's pictures had meaning when related to other languages and established associations with different historical times. To the extent that teachers dialogue with other areas of knowledge, constitutes a theoretical basis that allow the use of images in teaching history.

Keywords: Teaching of History; Picture; Jean-Baptiste Debret.
\end{abstract}

$\mathrm{Na}$ sociedade contemporânea, as diversas manifestações visuais adentram os espaços sociais, entre eles a escola, que, por sua vez, ainda privilegia a narrativa textual. Mesmo o texto escrito sobrepondo-se ao texto imagético, a imagem é fonte de pesquisa para muitos historiadores desde a segunda metade do século XX, e, principalmente, considerada um documento importante como recurso pedagógico em sala de aula. Dessa maneira, verificou-se como está sendo utilizada a produção iconográfica de Jean-Baptiste Debret como ferramenta de ensino-aprendizagem pelos professores de História, na educação básica, no Liceu do Ceará, situado no bairro Jacarecanga, em Fortaleza.

Buscamos compreender como os professores fizeram o encaminhamento da leitura dessas imagens de Debret com seus alunos, pois imagens não servem apenas como ilustração da narrativa histórica, mas revelam o real, ao serem contextualizadas. Para isso, elaboramos um questionário sobre o uso de iconografias, respondido individualmente no segundo semestre de 2010 e analisado na perspectiva de alguns teóricos. A iconografia como registro histórico precisa ser motivo do diálogo contínuo com os que ensinam História, e, para tal, propomos a reflexão acerca do referido tema.

Nesta escritura, utilizou-se o conceito de representação sugerido em Roger Chartier (2002; 1991) para uma análise baseada nas práticas culturais, nos contextos de produção, que, por sua vez, remetem a sensibilidades, símbolos e sinais apreendidos pelos sentidos, e, no caso do estudo das imagens, adentra a dimensão da cultura, instiga o historiador a ir além dos acontecimentos

*Endereço eletrônico: germano.junior@uece.br

**Endereço eletrônico:adrianocecatto@uern.br 
representados (PESAVENTO; SANTOS; ROSSINI, 2008). Buscou-se entender o material visual (Debret) e discutir acerca da sua produção e de seu consumo, pois as imagens também informam, sendo necessário contextualizá-las.

A utilização de imagens como recurso pedagógico no ensino de História destaca-se com frequência e exige dos professores um tratamento metodológico específico, que varia de acordo com a escolha da categoria imagética e com os objetivos propostos para o desenvolvimento de temáticas.

Dividimos o texto em duas partes. Primeiramente, estabelecemos relação entre História e imagem, conceituando e relacionando a imagem na pesquisa em História. No segundo momento, situamos as imagens de Debret e sua relação com a História e o ensino, analisando o uso de suas imagens pelos professores de História do Liceu do Ceará.

\section{História e imagem}

Peter Burke (2004), em seu livro Testemunha Ocular, estabeleceu uma discussão sobre a atitude que deve o historiador ter ante a utilização da imagem como fonte de pesquisa, atentando para sua evidência, mensagem e intencionalidade. $\mathrm{O}$ autor sugere utilizá-la como fonte importante para a pesquisa em História, a fim de romper com as concepções tradicionais, até porque a sociedade contemporânea se caracteriza pelo visual; vive-se numa sociedade imagética.

No que concerne, porém, a linguagens e fontes de estudo diferentes na História, historiadores como Peter Burke (2004, p.12) apontam para a existência de uma "invisibilidade visual", deixandose de tratar a imagem como evidência histórica. "Imagens nos permitem "imaginar" o passado de forma mais vivida [...] Embora os textos também ofereçam indícios valiosos, imagens constituem-se no melhor guia para o poder de representações visuais nas vidas religiosas e política de culturas passadas" (BURKE, 2004, p.17).

Compreende-se por imagem uma forma de linguagem para representar determinado objeto por meio de registros históricos: "[...] de ícones, de imagens pintadas, desenhadas, impressas ou imaginadas e, ainda, esculpidas, modeladas, talhadas, gravadas em material fotográfico e cinematográfico" (PAIVA, 2006, p.17). O termo iconografia esteve relacionado estritamente à história da arte até as décadas de 1920 e 1930, e remete ao estudo da origem e formação das imagens. Os historiadores da arte desse período priorizavam o conteúdo intelectual dos trabalhos, visando a compreender os aspectos implícitos.

Diferentemente de outros documentos, as imagens foram criadas para transmitir uma mensagem própria. Por esse motivo, torna-se necessário estudar primeiramente os produtores ou realizadores das imagens que se pretende analisar, apesar das fragilidades impostas naturalmente por esse tipo de documento. Segundo Paiva (2006, p.31), "ler uma imagem sempre pressupõe partir de valores, problemas, inquietações e padrões do presente, que, muitas vezes, não existiram ou eram muito diferentes no tempo e da produção do objeto, e entre seu ou seus produtores".

$\mathrm{Na}$ perspectiva de Burke (2004, p.20), "independente de sua qualidade estética, qualquer imagem pode servir como evidência histórica". Daí a importância de considerar seu testemunho do passado como valor real, assim como fazer relações com outros documentos. As imagens "oferecem acesso a aspectos do passado que outras fontes não alcançam" (BURKE, 2004, p.233). Como qualquer fonte histórica, as imagens respondem a perguntas que a elas são feitas, visto que "é necessário, portanto, saber fazer as indagações e saber escutar as respostas dadas pelo documento" (PAIVA, 2006, p.61). Toda imagem possui uma história, sendo o contrário também verdadeiro.

Nessa perspectiva da história cultural, Pesavento, Santos e Rossini (2008, p.99), ao relatarem sobre o trabalho com imagem, apontam para a necessidade de olhar para além daquilo que é mostrado, sugere pensar as iconografias como elaboração simbólica por se ter em mente algum ou alguns destinatários. Imagens são, sobretudo, ações humanas que, por meio da história, empenham-se em criar um mundo paralelo de sinais. São, pois, representações da realidade que se colocam no lugar das coisas, dos seres humanos e dos acontecimentos do mundo (PESAVENTO; SANTOS; ROSSINI, 2008, p.100).

Isso implica compreender a imagem como portadora de significados constituídos, na medida em que quem a observa e pensa estabelece relações, significados e valores desde o seu presente, o que requer a sensibilidade para compreender a "caminhada" do ser humano em tempo, espaço e contexto específicos. Contribuindo com essa reflexão, Borges (2003, p.80) diz que "a imagem é uma representação do mundo que varia de acordo com os códigos culturais de quem a produz".

Tanto as imagens como as narrativas 
textuais são portadoras de informações. Segundo Manguel (2001, p 21), por meio de ambas, é possível chegar à compreensão da existência, do real. Somos feitos de imagens e de palavras: "as imagens que formam nosso mundo são símbolos, sinais, mensagens e alegorias." E a imagem como representação remete à condição de ambivalência, ficando entre o real representado e o sentido que se insinua no ato da pesquisa, no contato com o objeto pesquisado. Como portadoras de um imaginário de sentido, as iconografias possibilitam adentrar um passado, por serem

[...] sedutoras, captando o olhar, de modo a envolver aquele que as contempla; são mobilizadoras, instigando à ação, por vezes mesmo de forma impensada e imediata; proporcionam a evasão, libertando a imaginação para fora do campo da imagem vista, de forma a conduzir o pensamento para outras instâncias imaginárias; são evocativas, despertando a memória $e$ conectando a outras experiências; têm, ainda, um poder cognitivo, traduzindo uma forma de saber sobre o mundo para além do conhecimento científico (PESAVENTO; SANTOS, ROSSINI, 2008, p.106).

Evidentemente, na pesquisa com imagens, deve o historiador se ater à percepção dos seres humanos de determinada cultura ou sociedade acerca da realidade em que vivem ou viveram, seus valores, hábitos.

Nos Annales (1929) ampliou-se a concepção de fonte na pesquisa em História e, consequentemente, sua utilização para o ensino. Para a prática contemporânea do ensino de História, há a necessidade de se trabalhar cada vez mais documentos históricos em sala de aula, e isso exige do professor a ampliação da ideia de documento e o seu uso no cotidiano. Conforme apontam Schmidt e Cainelli (2004, p.95), o professor não poderá mais se restringir ao documento escrito, "mas introduzir o aluno na concepção de documentos iconográficos, fontes orais, testemunhos da história local, além das linguagens contemporâneas, como cinema, fotografia e informática".

Os anos de 1980, com publicações realizadas por pesquisadores dos EUA sobre iconografias como fonte histórica, possibilita seus historiadores ampliação das pesquisas e, consequentemente, o uso de imagens no ensino. Paiva (2006, p.17) aponta a iconografia como importante fonte de pesquisa em História, desde que utilizada adequadamente, levando em consideração as suas particularidades e limites. "São registros com os quais os historiadores e professores de História devem estabelecer um diálogo contínuo". Nessa perspectiva, constata-se um crescimento significativo do uso de fontes de natureza não escrita, pois os documentos "não falam por si", constatando-se que "as armadilhas de um documento audiovisual ou musical podem ser da mesma natureza das de um texto escrito" (NAPOLITANO, 2005, p.239). As fontes audiovisuais, como qualquer tipo de fonte, portam em si uma tensão entre a evidência e representação.

Bittencourt alerta para a importância do tratamento metodológico de iconografias em sala de aula, sugerindo aos professores a valorização das imagens, seja qual for a origem de sua produção. Segundo a autora, o problema atual não está na falta de materiais para serem trabalhados no ensino de História, até porque se vive no século XXI num cenário marcado pela informatização, mas reside no "tratamento metodológico que esse acervo iconográfico exige, para que não se limite a ser usado apenas como ilustração para um tema ou recurso para seduzir um aluno acostumado com a profusão de imagens e sons do mundo audiovisual"(2009, p.360). Assim, a imagem como fonte de pesquisa em história é constante e não mais limitada aos auspícios específicos dos historiadores da arte.

Atualmente muitos estudos sobre o ensino de História são realizados no Brasil, principalmente no tocante às metodologias e às novas linguagens. Detectam-se, no entanto, resistências em relação ao emprego de iconografias. Por sua vez, Bittencourt (2009) propõe pensar as modificações que ocorreram na produção iconográfica com a influência da informática, saindo do âmbito dos historiadores da arte e adentrando a perspectiva da história social e cultural. Nesse sentido, as mudanças socioculturais influenciam e permitem mudanças no ensino de História, na medida em que as imagens e outras novas linguagens somam-se a outras fontes,considerando que "a sala de aula não é apenas o espaço onde se transmitem informações, mas o espaço onde se estabelece uma relação em que os interlocutores constroem significações e sentidos" (SCHMIDT e CAINELLI, 2004, p.31). Fica evidente a necessidade presente de se repensar o uso da imagem como fundamento e método de ensino, principalmente por possibilitar o estabelecimento da constituição de sentidos entre os 
estudantes e as iconografias trabalhadas.

É reconhecido o fato de que as imagens, sendo portadoras de informações, evidências históricas, podem e devem ser relacionadas com outras linguagens, mesmo apresentando suas fragilidades. Por isso, não podem ser usadas somente como ilustração, mas precisam ser somadas a outros documentos para ampliar a "leitura" sobre o mundo.

\section{Imagens de Debret e o ensino de história}

A Missão Artística Francesa, chegando à cidade do Rio de Janeiro, em 1816, propunha constituir e celebrar a imagem da Corte Portuguesa, que reinava no Brasil num contexto político diferente. Além do envolvimento com decorações festivas e grandes solenidades públicas, esses artistas contribuíram, juntamente com engenheiros, "para o engrandecimento político da corte perante seus súditos, com a construção de arcos de triunfo efêmeros, pinturas e suntuosas iluminações espalhadas pela capital carioca do novo Reino" (DIAS, 2006, p.245). Jean-Baptiste Debret, como membro desse grupo, procurou exercer o mesmo papel que desempenhou na França, ondese dedicou a representações pictóricas das campanhas militares de Napoleão Bonaparte, razão por que as pinturas tiveram a função de perpetuar o lado humanístico do Imperador e sua superioridade, retratando os grandes feitos nas batalhas com pintura de cunho celebrativo. Inspirado na tradição neoclássica italiana, Jean-Baptiste Debret fez parte de um grupo que pintou as "glórias" napoleônicas. Esse estilo de pintura o inspirou em seus trabalhos futuros, na constituição de retratos que destacassem personagens, hábitos e costumes da população, porém, no Brasil, ressaltou em suas produções a nova condição política do império, exaltando as nuanças desse período.

Jean-Baptiste Debret, formado pela Escola Francesa de Arte, registrou o cotidiano do Brasil transpondo a perspectiva da Corte. A escola de Belas Artes do Rio de Janeiro se propôs implantar valores, hábitos e costumes europeus que pudessem elevar o Brasil à categoria de "civilizado". Sua produção, tanto iconográfica quanto escrita, possibilitou o entendimento do Brasil com o enfoque no cotidiano, com características da cultura de literatura de viagem, que tinha por objetivo informar o continente europeu acerca dos povos ainda "não civilizados". E, apesar do preconceito cultural, descreveu o País e suas múltiplas culturas étnicas em discurso de processo de desenvolvimento. Dessa forma, podemos reconhecer que sua produção iconográfica contribuiu para o entendimento da constituição do Brasil na Europa.

A literatura de viagem de Debret insere-se no âmbito da literatura em voga no século XVIII, tornando acessíveis aos europeus informações sobre parte do mundo e dos povos ainda desconhecidos. Usou o termo pitoresco para reconstituir as particularidades do povo brasileiro, que ia além do aspecto exótico da natureza e se fazia presente nos traços que identificavam um estado civilizatório digno de atenção. "Ao privilegiar as imagens em seu discurso, Debret garantia tal fidelidade através do testemunho" (LIMA, 2004, p.34).

O artista Debret destacou-se pela produção da vida política da Corte, voltado para o âmbito oficial, com muitas aquarelas retratando a família real; no entanto, "em paralelo a suas atividades como pintor oficial e cenógrafo da Monarquia, Debret cumpre a sua trajetória de membro fundador e pintor de história da academia" (LIMA, 2007, p.100). Contribuiu com a formação para a arte na medida em que sugeriu aos novos artistas a liberdade e autonomia para a elaboração da própria arte, promovendo sempre grandes exposições no Rio de Janeiro. Merece destaque, no entanto, sua documentação por meio da arte cotidiana empregada de originalidade nos registros de rua. A maioria dos viajantes registrava a arquitetura e a topografia da cidade; já com Debret, os habitantes e o povo carioca, foram desenhados em primeiro plano.

Debret considerava necessário mudar os rumos do Brasil, esquecer o passado ligado às amarras coloniais, integrar o País à realidade internacional e atuar nos campos político, econômico e cultural, a fim de alicerçar o Segundo Império sob a perspectiva de uma nação e de um povo brasileiro. Deste modo, descreveu um país a caminho da "civilidade". A sua produção artística é utilizada com frequência nos manuais didáticos de História da educação básica, compondo a temática da vinda da Família Real Portuguesa ao Brasil.Analisar essa produção iconográfica e utilizála no processo de ensino-aprendizagem poderá proporcionar o diálogo com diferentes linguagens e temporalidades históricas. Com esse intuito, procuramos entender como docentes utilizam essas imagens no ensino de História.

Para compreender o emprego da produção 
iconográfica de Debret pelos professores, foi aplicado e analisado um questionário respondido por docentes acerca da concepção e uso dessas imagens em sala de aula. A aplicação do questionário como técnica de pesquisa teve como foco os professores de História, no ensino médio do Colégio Estadual Liceu do Ceará, situado na praça Fernandes Vieira, no bairro Jacarecanga, na cidade de Fortaleza. A escolha dessa instituição decorre do seu reconhecimento social e da sua importância histórica para a educação no Estado do Ceará, por ter sido o primeiro Liceu do Estado a ser implantado.

Em relação à escolha dos professores, entrevistamos sete deles, que fazem parte do quadro de colaboradores, visto que o Colégio trabalha com o ensino médio e com muitas turmas. Com efeito, o número de docentes concentrados na mesma instituição pública de ensino contribuiu para nossa escolha.

Detivemo-nos no ensino médio por que a Instituição trabalha somente com este nível, que compõe a educação básica. Comumente, no transcorrer da disciplina História, os alunos e professores deparam muitas imagens postadas nos livros didáticos, material de fácil acesso nas escolas públicas, pelo menos nas grandes cidades brasileiras. Entre as muitas imagens impressas, as pinturas de Debret se fazem presentes num momento histórico importante do inicio do século XIX: com a chegada da Família Real Portuguesa ao Brasil.

As questões que analisaremos foram elaboradas na perspectiva de entender o processo de ensino, utilizando-se das imagens de Debret, visando a analisar a compreensão dos professores acerca do conceito de imagem e sua utilização em sala de aula. Ao relatar sobre a necessidade de se repensar o uso de documentos no cotidiano escolar, Schmidt e Cainelli $(2004$, p. 95) sugerem que o próprio professor amplie sua concepção e uso do documento, o que, por sua vez, dependerá das iniciativas docentes. Trata-se também do cuidado com a sedução que a imagem provoca no leitor, principalmente pela possibilidade de ocorrer a ausência de fundamentação teórica e de método, que segundo Paiva (2006, p.17), “[...] ela é uma fonte como qualquer outra e, assim como as demais, tem que ser explorada com muito cuidado. Não são raros os casos em que elas passam a ser tomadas como verdade $[\ldots]$. ."

A aplicação de questionário vem ao encontro da necessidade de se notar as iniciativas e a forma de condução do trabalho com imagens, atentando para o risco do anacronismo, "isto é, ler a imagem, a representação, sem relativizá-la no tempo, é lê-la a partir de valores, de padrões e de certos comportamentos que não existiam na época em que foi produzida ou não fazia parte do universo cultural de onde ela provém" (PAIVA, 2006, p.89). As representações iconográficas, assim como outras fontes, são lidas a partir do presente, passíveis de indagações diferentes, de variadas leituras. Nessa perspectiva, o encaminhamento da leitura de imagens em sala de aula demanda a fundamentação necessária que possibilite ao docente encaminhar a leitura dessa categoria de narrativa. Essa fundamentação refere-se a autores que sugerem categoriais de análise de imagens.

Os questionários foram encaminhados a sete docentes do Liceu do Ceará, para que pudessem responder no prazo de uma semana. Entre esses, somente um não entregou, alegando que não trabalhava com imagens. O questionário aplicado foi composto por nove questões referentes à concepção sobre imagem, o modo como se utilizou metodologicamente e, especificamente, a utilização da produção iconográfica de Jean-Baptiste Debret.

Ao analisar as respostas dos professores acerca do uso de imagens, consideraremos o conceito de representação e da própria história, pois "o historiador passa a buscar na imagem as sensibilidades de uma época, expressas nas formas de imaginar e representar o mundo [...]" (PESAVENTO; SANTOS; ROSSINI, 2008, p.114). A proposta da história cultural é de que se avance para uma leitura além do aspecto estético, do figurativo. Interessa-nos entender como os professores utilizam imagens para ensinar e as concepções que se tem acerca desse conceito. O conceito de representação tem sua origem na Sociologia, especificamente em Marcel Mauss e Emile Durkheim, e foi apropriado por Roger Chartier entre os historiadores. Segundo Bittencourt (2009, p.363), "a utilização desse conceito visa superar a concepção que as imagens fixas ou em movimento têm sido a base da informação e entendidas como o real, como o fato histórico". Roger Chartier utiliza-se da representação, rompendo assim, gradativamente, com a história das mentalidades e introduzindo a dimensão da História Cultural; impulsionou uma história plural, privilegiando as manifestações da cultura e instrumentalizando o historiador a identificar como em diferentes lugares e momentos da história determinadas realidades são pensadas e lidas. 
Segundo Vainfas (1997, p.155), no conceito de representação elaborado por Chartier, "o social só faz sentido nas práticas culturais e as classes e grupos só adquirem alguma identidade nas configurações intelectuais que constroem, nos símbolos de uma realidade contraditória representada etc". Conforme sugere Chartier (1991, p.183-184),

\section{[...] a história cultural separa-se sem dúvida de uma dependência demasiadamente estrita de uma história social dedicada exclusivamente ao estudo das lutas econômicas, porém opera um retorno hábil também sobre o social, pois centra a atenção sobre as estratégias simbólicas que determinam posições $e$ relações e que constroem, para cada classe, grupo ou meio, um ser-percebido constitutivo de sua identidade.}

Para Chartier (1991, p.184), a relação de representação é "entendida como relação entre uma imagem presente e um objeto ausente [...]." Para o estudo da cultura, segundo Pesavento, Santos e Rossini(2008, p.12-13), o conceito de representação é fundamental, pois "os homens elaboram ideias sobre o real, as quais se traduzem em imagens, discursos e práticas sociais que não somente qualificam o mundo como também orientam o olhar e a percepção sobre a realidade". Ao mesmo tempo, remete a sensibilidades, símbolos e sinais apreendidos pelos sentidos, e, no caso do estudo das imagens, adentra a dimensão da cultura, instiga o historiador a ir além dos acontecimentos representados (pela estética) e entender a noção sobre o mundo e os homens acercada realidade em que vivem.

A utilização desse conceito para entender o uso de imagens antecede o próprio ensino, considerando que, para elaborar leituras de imagens, se faz necessário adentrar o campo simbólico e entender a realidade e o contexto da produção, bem como suas intencionalidades. Essas intencionalidades permitem, primeiramente, privilegiar dimensões além da arte em si, percebendo que existe uma relação de produção e consumo. Interessa-nos detectar,com suporte desse conceito, o modo como os professores em suas respectivas práticas elaboram leituras de imagens.

As imagens utilizadas no ensino de História não deixam de expressar compreensões de mundo. Até o século XIX, havia uma atitude dos artistas diante da composição da imagem de grandes líderes, no sentido de convencer e demonstrar afinidade com o momento político ou religioso que se pretendia representar. Portanto, as imagens são um tipo de linguagem dotada de sentido, que pretende comunicar algo, não se tratando mais de um simples retrato, mas sim da representação de algo ou de alguém.

A abertura a outras linguagens, segundo Burke (1992), faz com que os historiadores estudem o material visual e possibilitem a discussão acerca da sua produção e de seu consumo como atividades sociais, econômicas e políticas. As imagens também informam, bastando saber um pouco mais sobre o produtor e seu mundo, seu contexto.

No século XIX, cabia ao historiador extrair informações dos documentos, sem nada acrescentar. Por isso a utilização das imagens como fonte histórica pelos autores, inclusive em livros didáticos, reforçava e legitimava a autoridade do texto escrito. Certas imagens apresentadas para os alunos em sala de aula, segundo Schmidt e Cainelli (2004, p.92), "tornaram-se canônicas", por terem sido colocadas como verdade, esquecendo-se de que as imagens não são o real, mas sim representação. Essas imagens podem passar pelo processo de desconstrução na medida em que são utilizadas como documento histórico para o ensino de História, situando o aluno no centro do processo de ensino-aprendizagem.

Considerando os dados coletados com a aplicação do questionário, a primeira questão solicitava que redigissem sobre o que compreendem por imagem. As respostas demonstram que parte dos professores concebe a imagem como signo, representação do real. Também exprimem concepções mais amplas ao considerarem o processo de produção da imagem. Retratam ser a representação do real e, ao mesmo tempo, ilustração de assuntos ou temas. Pesavento, Santos e Rossini (2008, p.99) sugerem que as imagens contêm dimensões simbólicas e seu significado vai além daquilo que nos é mostrado, pois são "um tipo de linguagem, ou seja, atestam uma intenção de comunicar, que é dotada de um sentido e é produzida a partir de uma ação intencional". Remetem-nos a pensar a imagem como "ações humanas que, através da história, empenham-se em criar um mundo paralelo de sinais. São, pois, representações da realidade que se colocam no lugar das coisas, dos seres e dos acontecimentos do mundo" (PESAVENTO; SANTOS; ROSSINI, 2008, p.100). A imagem é de fato portadora de 
significado, precisando ser compreendida como ação humana representando a realidade. Essas imagens, segundo Paiva (2006, p.17), "são registros com os quais os historiadores e os professores de História devem estabelecer um diálogo contínuo".

De modo geral, percebe-se que embora o conceito de imagem seja bastante amplo, não está devidamente explicita para os docentes essa concepção. Um dos entrevistados não quis responder ao questionário, alegando não ser do campo da História, e sim da História da Arte.

Outra pergunta dizia respeito ao emprego de algum tipo de imagem nas aulas de História e que imagem utilizou. Com exceção de um professor, todos apontaram alguma forma de trabalho, seja com filme, fotografia ou pinturas.

Somente um professor entrevistado descreveu a utilização da abordagem das imagens presentes no livro didático, fato demonstrativo de que ainda se privilegia o texto em detrimento da imagem, pois esta tem o papel de ilustrar o texto. Segundo Paiva (2006, p.27), há de se considerar "além da análise textual, a leitura da iconografia como elemento fundante do saber histórico em sala de aula".

No tocante à abordagem metodológica para o uso da imagem, identificamos em boa parte dos docentes a falta de definição em termos metodológicos, no trabalho com a leitura das imagens. Detectamos o fato de que não foram consideradas as especificidades dessa linguagem, portanto, não se apropriaram ou não formularam um método específico para o trabalho. A imagem é uma narrativa, portanto, não pode ser concebida como mera ilustração. Hoje, o campo iconográfico é muito extenso, envolvendo muitos tipos de imagens: "Os métodos de análise dessas diferentes imagens necessitam estabelecer relações com outras fontes, notadamente com os textos escritos" (BITTENCOURT, 2009, p.364). Se a imagem não é a realidade, e sim sua representação, torna-se necessário recorrer a outras ferramentas que possibilitem a ampliação da leitura da imagem estudada. Nesse caso, o texto escrito é imprescindível.

A imagem, porém, não esgota em si mesma, pois sempre existe a possibilidade de novas leituras interpretativas desse tipo de documento; sempre é possível apreender algo mais, pois "há lacunas, silêncios e códigos que precisam ser decifrados, identificados e compreendidos" (PAIVA, 2006, p.19). Torna-se importante esse tipo de trabalho em sala de aula, na medida em que contribui para a desconstituição de certas imagens "canonizadas a respeito do passado" (SCHIMIDT; CAINELLI, 2004, p.92). E nessa desconstituição, é possível o fato de que o problema se encontra no tratamento metodológico das imagens, pois

[...] independente da origem da imagem, o problema central que se apresenta para os professores é o tratamento metodológico que esse acervo iconográfico exige, para que não se limite a ser usado apenas como ilustração para um tema ou como recurso para seduzir um aluno acostumado com a profusão de imagens e sons do mundo audiovisual (BITTENCOURT, 2009, p.360361).

Isso denota que, embora a sociedade contemporânea esteja permeada pelo excesso de imagens e o próprio ensino de História apresente uma variedade de iconografias nos materiais didáticos, segundo Bittencourt (1997, p.70), "a reflexão sobre $o$ papel que efetivamente desempenham no processo de ensino $\mathrm{e}$ aprendizagem é escassa".

A questão seguinte dizia respeito à fundamentação teórica para o desenvolvimento desse tipo de trabalho. Embora dois professores tenham demonstrado conhecer teóricos que orientam essa metodologia, detectamos considerando os escritos dos autores ${ }^{1}$ citados pelos entrevistados-, que não possuem conhecimento teórico suficiente e necessário para o que poderíamos chamar de "bom uso" das imagens. Percebeu-se também a necessidade de buscar teóricos de outras áreas do conhecimento (História da Arte). "As imagens, assim como as histórias, nos informam [...] são símbolos, sinais, mensagens e alegorias" (MANGUEL, 2001, p.21). Nessa perspectiva, as imagens necessitam ser lidas em seus respectivos contextos de produção, e, para tal, o diálogo com outras áreas do conhecimento tornase essencial e, principalmente, os teóricos que contribuem para ampliar a leitura sobre o objeto.

Essa fundamentação teórica está intimamente ligada à ampliação da ideia de documento histórico e seu respectivo uso em sala de aula. O conhecimento teórico acerca do uso de imagens é fundamental para auxiliar o estudante na utilização dos documentos iconográficos, muito embora não seja suficiente

\section{[...] o professor ampliar o uso de}


documentos; também deve rever seu tratamento, buscando superar a compreensão de que ele serve apenas como ilustração da narrativa histórica e de sua exposição, de seu discurso. A concepção renovadora de documento e de seu uso em sala de aula parte do pressuposto de que o trabalho com documentos históricos pode ser ponto de partida para a prática de ensino de História. Nessa perspectiva, os documentos não serão tratados como fim em si mesmos, mas deverão responder às indagações e às problematizações de alunos e professores, com o objetivo de estabelecer um diálogo com o passado e o presente, tendo como referência o conteúdo histórico a ser ensinado (SCHIMIDT; CAINELLI, 2004, p.95).

Esse cuidado com a formação e a flexibilidade para dialogar com outras áreas do conhecimento precisam se fazer presentes, pois, certamente, novas ferramentas possibilitam a ampliação do poder de leitura e análise de iconografias, contribuindo para um novo pensar e uma nova prática no ensino.

Ao perguntar aos docentes sobre a utilização das imagens de Debret em sala de aula, três professores relataram utilizar somente as que retratam a escravidão e, dentre esses três, um deles afirmou a necessidade da imagem para suprir lacunas da história. Um dos professores trabalhou "indiretamente" as iconografias nos livros didáticos.É bem verdade que o artista retratou a população negra e mestiça, no entanto foi um trabalho secundário, visto que seu compromisso estava associado diretamente com os eventos políticos da Corte Portuguesa. Assim, percebe-se que suas imagens são utilizadas com maior frequência para fazer leitura sobre a escravidão. Podemos detectar a limitação do uso das imagens a uma só temática: a escravidão.

Observando as respostas dos professores, torna-se imprescindível estabelecer relações com outras fontes, principalmente a escrita, a fim de ampliar as possibilidades de leituras históricas com a utilização da iconografia como metodologia de ensino. Com efeito, Burke (2004, p.20) sugere que "independentemente de sua qualidade estética, qualquer imagem pode servir como evidência histórica". Por tal motivo, não pode ser ignorada pelos historiadores. Pensá-la além das entrelinhas é necessário, pois, segundo Burke (2004, p.238), os historiadores devem usá-las com uma perspectiva diferente daquele de quem a produziu, "como pistas para informações que os produtores de imagens não sabiam que eles sabiam, ou para suposições que eles não estavam conscientes de possuir". Em nosso caso, o período colonial foi um espaço de produção e intencionalidades, e entender a imagem como representação permite a leitura dessas intencionalidades. Segundo Pesavento, Santos e Rossini (2008, p.109),

[...] textos e imagens, como narrativas que são, fazem-se acompanhar de saberes específicos e de habilidades técnicas próprias: o ato de ler, com seu simbolismo de códigos, analogias e convenções; a composição da imagem, com suas técnicas, regras, convenções e formas de educação do olhar.

Outra pergunta sugeria pensar além dos aspectos históricos e adentrar a estética da imagem. Essa dimensão pressupõe que o historiador vá além do acontecido registrado e compreenda a percepção dos homens sobre a realidade histórica em que viveram, uma atitude interessante, na medida em que possibilita ao historiador poder passar "a buscar na imagem as sensibilidades de uma época, expressas na forma de imaginar e representar o mundo, sensibilidades essas que tornariam uma época diferente das demais" (PESAVENTO; SANTOS; ROSSINI, 2008, p.114). Dois professores apresentaram aos seus alunos os elementos europeus contidos nas imagens. Os demais justificaram o fato de não trabalharem melhor esse viés estético pela falta de tempo, e até mesmo pela ausência de subsídios que permitam uma leitura mais aprofundada. A metade dos discentes não trabalhou referida dimensão.

O artista Debret apresenta elementos estéticos que caracterizam a sua formação, como nos sugere Zamboni (1998, p.30):

$O$ desenho de Debret a respeito do apresamento indígena nos campos de Curitiba não deixa de ser o olhar europeu sobre um povo e um dado local. Se nos detivermos na representação das figuras femininas e das crianças, nos traços das pernas, das formas do corpo e do cabelo, concluiremos que elas estão mais próximas 
das figuras européias do que da mulher indígena.

Podemos concluir, a partir das respostas, que poucos entrevistados têm conhecimento da história e da estética das obras de Debret, portanto, não possuem fundamentação teórica que lhes possibilite fazer uma leitura mais abrangente das imagens. Dessa maneira, há de se considerar que imagem não pode continuar sendo tratada como mera ilustração de textos ou da própria fala dos professores.

Ao trabalhar com a dimensão estética do visual, bela ou feia, cativante ou aterradora, a imagem produz, de forma efetiva e direta, a emoção e desperta os sentidos [...] Vivemos, cada vez mais, em um mundo tomado pelas imagens, onde todos vêem imagens, mas nem todos podem, ou sabem, lê-las (PESAVENTO; SANTOS; ROSSINI, 2008, p.119).

Além desse aspecto, a outra dimensão abordada entre os professores refere-se à aprendizagem dos alunos e à reação destes à metodologia de trabalho. Notamos que os docentes detectaram melhoras no âmbito da aprendizagem, seja na concentração, na melhoria em relação à sistematização dos conteúdos, ou até mesmo vinculando imagens com outros conteúdos e com aspectos do tempo presente. "Embora os textos também ofereçam indícios valiosos, imagens constituem-se no melhor guia para o poder de representações visuais nas vidas religiosa e política das culturas passadas" (BURKE, 2004, p.17). Mostrou-se, porém, nas respostas dos professores o cuidado com o anacronismo, que, por sua vez, é fragilidade que pode ser superada na medida em que a leitura da imagem passe pela contextualização de seus produtores e o tempo da produção. A aprendizagem passa pela capacidade de estabelecer associações e comparações, razão pela qual se torna significativo colocar os estudantes em contato com documentos históricos. Como sugeriu Schmidt e Cainelli (2004, p.94),

[...] o contato com as fontes históricas facilita a familiarização do aluno com formas de representação das realidades do passado e do presente, habituando-o a associar o conceito histórico à análise que o origina e fortalecendo sua capacidade de raciocinar baseado em uma situação dada.

A última questão se referia aos resultados alcançados pelos discentes em relação ao uso de imagens.A maioria dos entrevistados observou que a aprendizagem passou a ser mais significativa no ensino de História, e que o interesse pelo estudo do conteúdo, ou seja, o poder de associação, de análise critica, melhorou, motivando os estudantes.

A leitura de imagens em sala de aula será sempre um exercício constante, pois "ler uma imagem sempre pressupõe partir de valores, problemas, inquietações e padrões do presente, que, muitas vezes, não existiram ou eram muito diferentes no tempo da produção do objeto, e entre seu ou seus produtores" (PAIVA, 2006, p.31). Com efeito, Bittencourt (2009, p.368) aponta para a necessidade de escolher imagens a serem analisadas com os alunos, priorizando as mais fortes, representativas, capazes de causar "impacto visual" e que possam motivar a sala de aula à leitura dessa categoria de documento. Consoante Burke (2004, p.18),

É desnecessário dizer que o uso do testemunho de imagens levanta muitos problemas incômodos. Imagens são testemunhas mudas, e é difícil traduzir em palavras o seu testemunho. Elas podem ter sido criadas para comunicar uma mensagem própria, mas historiadores não raramente ignoram essa mensagem a fim de ler as pinturas nas 'entrelinhas' e aprender algo que os artistas desconheciam estar ensinando. Há perigos evidentes nesse procedimento. Para utilizar a evidência de imagens de forma segura, e de modo eficaz, é necessário, como no caso de outros tipos de fonte, estar consciente de suas fragilidades.

Na utilização das iconografias de Debret pelos professores, embora as escolhas tenham sido concentradas na representação da escravidão, a metade dos docentes demonstrou fragilidades metodológicas no encaminhamento do trabalho com seus alunos, principalmente pela carência de formação. Por sua vez, essas fragilidades podem estar relacionadas à falta de fundamentação teórica.

A produção de Debret, aliada a um momento histórico específico, com os valores dos 
homens de seu tempo, possibilita entender as intenções que dão sentido as suas pinturas. Ao reconhecer os elementos que compõem as iconografias de Debret, percebe-se que os professores se tornam aptos a trabalhar com qualquer categoria de imagem no ensino de História. Entrementes, as lacunas de cunho de fundamentação teórica e metodológica podem comprometer a condução de trabalho com essa categoria de documento histórico.

As crianças e jovens de hoje, que estão em sala de aula, são marcados em seu cotidiano pelas imagens, ganhando destaque a dimensão virtual criado pela informática e a vasta possibilidade que esse campo oferece. Em contrapartida, no ensino de História, detectamos o fato de que ainda prevalece a narrativa escrita, tendo o livro didático muitas vezes como único instrumento de conhecimento histórico, deixando-se de lado o uso das narrativas imagéticas que, segundo Burke (2004, p.17), "nos permitem imaginar o passado de forma mais vivida". Como anota Fonseca (2006, p.27), além da utilização textual, o uso da leitura de iconografias se faz elemento importante para a constituição do saber histórico em sala de aula.

Surge cada vez mais a necessidade de interpretação e contextualização da iconografia, percebendo-se as tensões entre o subjetivo e o social, traduzidos pela imagem como linguagem dotada de sentido simbólico e de representação. Assim, assevera Manguel (2001, p.27): "Vemos a pintura como algo definido por seu contexto; podemos saber algo sobre o pintor e sobre o seu mundo; podemos ter alguma ideia das influências que moldaram sua visão; se tivermos consciência do anacronismo, podemos ter o cuidado de não traduzir essa visão pela nossa".

\section{Considerações finais}

Procuramos entender o modo como os professores de História utilizam imagens em sala de aula, tendo como referência as pinturas produzidas por Debret no inicio do século XIX, por serem imagens muito presentes e, portanto, conhecidas pelos professores e até mesmo pelos alunos.

Observando as respostas obtidas com alguns professores da educação básica, as mudanças de concepções e de metodologias não são suficientes para garantir a transformação da prática de ensino.

Notamos que pouco se utiliza iconografias em sala de aula, e, mesmo entre os professores que a utilizam,eles nem sempre o fazem considerando a bibliografia (teóricos). Mesmo com o aumento significativo de estudos e publicações sobre o uso de variados documentos no ensino de História, permanece entre os docentes a opção por privilegiar o texto escrito.

Atitudes como a demonstrada pelo professor que não se sentiu livre para responder ao questionário, dizendo ser esse tipo de trabalho uma função da História da Arte, remetem a pensar que falta intercâmbio das disciplinas, o que só ocorrerá na medida em que surgir a necessidade de buscar fundamentação teórica. Também nos move a pensar, no entanto, na importância de gradativamente romper com o ensino tradicional, comprometendose com a renovação pedagógica.

Podemos detectar que o uso das imagens de Debret foi realizado pelos educadores que já se utilizaram de imagens em sala de aula, no entanto, o emprego das imagens foi realizado mesmo convivendo com a falta de fundamentação teórica e a limitação ao uso de iconografias voltadas para a escravidão, ignorando o contexto da Corte Portuguesa e os aspectos políticos como a representação do poder.

Apontamos para a necessidade de formação para trabalhar com iconografias, pois, embora se reconheça a imagem como narrativa importante para a produção do conhecimento histórico, sua pouca utilização pode estar relacionada diretamente à falta de fundamentação teórica.

Os professores que utilizaram imagem, no entanto, perceberam a necessidade da complementação com o texto escrito, além de reconhecerem que a aprendizagem se torna mais significativa entre os discentes.

As imagens como portadoras de informações, de evidências históricas, exprimem suas fragilidades, por isso não podem ser usadas somente como ilustração, mas somadas a outros documentos para ampliar a leitura sobre o mundo. Além disso, a imagem tem o potencial de permitir ao aluno o diálogo com outras temporalidades históricas, permitindo análise crítica, participativa e motivadora.

Torna-se fundamental compreender o contexto de produção, as intencionalidades de quem produziu determinada imagem, pois só assim será possível utilizar essa linguagem no ensino de História sem cometer erros, como o anacronismo. Conseguimos concluir que o uso de imagens é necessário na labuta do ensino de História, mas necessita de formação e conhecimentos específicos. 


\section{Notas}

1 Entre os entrevistados, dois docentes mencionaram os seguintes autores: Circe Maria Fernandes Bittencourt, Martha Abreu, Rachel Soihet, Selva Guimarães Fonseca. Mesmo assim, percebe-se que se limitaram a teóricos do ensino de História. O trabalho com essa categoria de linguagem permite e exige a interdisciplinaridade.

\section{Referências}

BITTENCOURT, Circe Maria Fernandes. Ensino de História: fundamentos e métodos.2.ed. São Paulo: Cortez, 2009.

. Livros didáticos entre textos e representações. In: BITTENCOURT, Circe Maria Fernandes (org.). O Saber histórico em sala de aula. São Paulo: Contexto, 1997.

BORGES, Maria Eliza. História \& Fotografia. Belo Horizonte: Autêntica, 2003.

BURKE, Peter (org). A escrita da história: novas perspectivas. São Paulo: Editora da Universidade Estadual Paulista, 1992.

BURKE, Peter. Testemunha ocular: história e imagem. Bauru, SP: EDUSC, 2004.

CHARTIER, Roger.O mundo como representação. Estudos Avançados,v.11, n.5, 1991, p.173-191.

A História Cultural: entre práticas e representações. Rio de Janeiro: Bertrand Brasil, 2002.

DIAS, Elaine. A representação da realeza no Brasil: uma análise dos retratos de D. João VI e de D. Pedro I, de Jean-Baptiste Debret. Anais do Museu Paulista. São Paulo: n. Sér. v.14. p. 243-261. Jan.jun. 2006.
FONSECA, Thais Nívia de Lima. História \& ensino de História. 2. ed. Belo Horizonte: Autêntica, 2006.

LIMA, Valéria Alves Esteves. Uma Viagem com Debret. Rio de Janeiro: Jorge Zahar Editor, 2004.

J.-B. Debret, historiador e pintor: a viagem pitoresca e histórica ao Brasil (1816-1839). Campinas: Editora da UNICAMP, 2007.

MANGUEL, Alberto. Lendo imagens: uma história de amor e ódio. São Paulo: Companhia das Letras , 2001.

NAPOLITANO, Marcos. A História depois do papel: os historiadores e as fontes audiovisuais e musicais. IN: PINSKY, Carla Bassanezi (org.). Fontes históricas. São Paulo: Contexto, 2005.

PAIVA, Eduardo França. História \& imagens. 2.ed. Belo Horizonte: Autêntica, 2006.

PESAVENTO, Sandra Jatahy; SANTOS, Nádia Maria Weber; ROSSINI, Miriam de Souza. Narrativas, imagens e práticas sociais: percurso em história cultural. Porto Alegre, RS: Asterisco, 2008 .

SCHIMIDT, Maria Auxiliadora; CAINELI, Marlene. Ensinar História. São Paulo: Scipione, 2004.

VAINFAS, Ronaldo. História das Mentalidades e História Cultural. In: CARDOSO, Ciro Flamarion; VAINFAS, Ronaldo (orgs). Domínios da História: Ensaios de Teoria e Metodologia. Rio de Janeiro: Elsevier, 1997.

ZAMBONI, Ernesta. Representações e Linguagens no Ensino de História. Revista Brasileira de História, v.18, n.36, p.26-34, São Paulo, 1998.

\section{Sobre os autores:}

Antonio Germano Magalhães Junior: Professor adjunto da UECE, leciona no programa de Pós-Graduação em Educação da UECE (PPGE). Graduado em Pedagogia (UFC) e História (UECE). Mestre e Doutor em Educação (UFC) e Pós-Doutor (UFRN).

Adriano Cecatto: Professor substituto da UERN, leciona no departamento de História do campus de Assú-RN. 
Graduado em História (UFPR) e Teologia (PUC-PR). Especialista em Metodologias do Ensino de História (UECE). Mestre em Educação (UECE).

Artigo recebido em junho de 2013

Artigo aprovado em outubro de 2013 